\title{
Gli1 enhances migration and invasion via up-regulation of MMP-11 and promotes metastasis in ER $\alpha$ negative breast cancer cell lines
}

\author{
Yeon-Jin Kwon • Douglas R. Hurst • \\ Adam D. Steg - Kun Yuan - Kedar S. Vaidya • \\ Danny R. Welch · Andra R. Frost
}

Received: 8 September 2010/ Accepted: 12 March 2011/Published online: 27 March 2011

(C) The Author(s) 2011. This article is published with open access at Springerlink.com

\begin{abstract}
Gli1 is an established oncogene and its expression in Estrogen Receptor (ER) $\alpha$ negative and triple negative breast cancers is predictive of a poor prognosis; however, the biological functions regulated by Gli1 in breast cancer have not been extensively evaluated. Herein, Gli1 was over-expressed or down-regulated (by RNA interference and by expression of the repressor form of Gli3) in the ER $\alpha$ negative, human breast cancer cell lines MDA-MB-231 and SUM1315. Reduced expression of Gli1 in these two cell lines resulted in a decrease in migration and invasion. Gli1 over-expression increased the migration and invasion of MDA-MB-231 cells with a corresponding increase in expression of MMP-11. Silencing MMP-11 in MDA-MB-231 cells that over-expressed Gli1 abrogated the Gli1-induced enhancement of migration and invasion. Sustained suppression of Gli1 expression decreased growth of MDA-MB-231 in vitro by increasing apoptosis and decreasing proliferation. In addition, silencing of Gli1 reduced the numbers and sizes of pulmonary metastases of
\end{abstract}

Electronic supplementary material The online version of this article (doi:10.1007/s10585-011-9382-z) contains supplementary material, which is available to authorized users.

Y.-J. Kwon · D. R. Hurst · A. D. Steg · K. Yuan ·

K. S. Vaidya - D. R. Welch · A. R. Frost ( $\square)$

Department of Pathology, University of Alabama at

Birmingham, Kaul Human Genetics Building, 720 20th Street

South, Birmingham, AL 35294, USA

e-mail: afrost@uab.edu

Y.-J. Kwon · D. R. Welch · A. R. Frost

Department of Cell Biology, University of Alabama at

Birmingham, Birmingham, AL 35294, USA

D. R. Hurst - D. R. Welch · A. R. Frost

Comprehensive Cancer Center, University of Alabama at

Birmingham, Birmingham, AL 35294, USA
MDA-MB-231 in an in vivo experimental metastasis assay. In summary, Gli1 promotes the growth, survival, migration, invasion and metastasis of ER $\alpha$ negative breast cancer. Additionally, MMP-11 is up-regulated by Gli1 and mediates the migration and invasion induced by Gli1 in MDA-MB-231.

Keywords Breast cancer · Gli1 · Gli-mediated transcription $\cdot$ MMP-11 $\cdot$ Invasion $\cdot$ Migration $\cdot$ Metastasis

$\begin{array}{ll}\text { Abbreviations } \\ \text { ANOVA } & \text { Analysis of variance } \\ \text { cDNA } & \text { Complementary deoxyribonucleic acid } \\ \text { DCIS } & \text { Ductal carinoma in situ } \\ \text { DMEM } & \text { Dulbecco's Modification of Eagle's Medium } \\ \text { DMSO } & \text { Dimethyl sulfoxide } \\ \text { DNase } & \text { Deoxyribonuclease } \\ \text { EGF } & \text { Epidermal growth factor } \\ \text { ERK } & \text { Extracellular signal regulated kinase } \\ \text { ER } \alpha & \text { Estrogen receptor } \alpha \\ \text { FBS } & \text { Fetal bovine serum } \\ \text { HRP } & \text { Horseradish peroxidase } \\ \text { IGF } & \text { Insulin like growth factor } \\ \text { kD } & \text { Kilodalton } \\ \text { MMP } & \text { Matrix metalloproteinase } \\ \text { MMTV } & \text { Mouse mammary tumor virus } \\ \text { MTT } & \text { 3-(4,5-Dimethylthiazol-2-yl)-2,5- } \\ & \text { diphenyltetrazolium bromide } \\ \text { NT } & \text { Non-targeting } \\ \text { PARP } & \text { Poly(ADP-ribose) polymerase } \\ \text { PCR } & \text { Polymerase chain reaction } \\ \text { PR } & \text { Progesterone receptor } \\ \text { QRT } & \text { Quantitative, reverse transcription PCR } \\ \text { RNA } & \text { Ribonucleic acid } \\ \text { RPLP0 } & \text { Ribosomal protein large 0 }\end{array}$


shRNA Short hairpin ribonucleic acid

siRNA Small interfering ribonucleic acid

TGF $\beta \quad$ Transforming growth factor $\beta$

Tris- $\mathrm{HCl}$ Tris(hydroxymethyl)aminomethanehydrochloric acid

\section{Introduction}

Gli1 is a zinc finger transcription factor and a member of the vertebrate Gli family. The Gli transcription factors, which in addition to Gli1 include Gli2 and Gli3, are effectors of the Hedgehog signaling pathway. The Gli transcription factors coordinately regulate Gli-mediated transcription [1]; however, Gli1 functions as the terminal and critical activator of Gli-mediated transcription [2]. Although Gli1 was first identified through its role as a transcriptional mediator of Hedgehog signaling, it is now known that Gli1 expression and activity are also modulated by other signaling pathways, including Transforming Growth Factor $\beta$ (TGF $\beta)$, Ras/ERK, and Wnt [3-6].

Gli1 plays an important role in the initiation and progression of several types of cancer. Gli1 was first identified by its amplification in human glioma [7]. Additionally, Gli1 drives the development of cancers associated with Gorlin's syndrome, which include basal cell carcinomas, medulloblastomas and rhabdomyosarcomas and result from inappropriate activation of Hedgehog signaling by mutations of pathway members [8]. Gli1 activity has also been shown to promote the growth, migration, invasion and/or metastasis of several other cancer types, including cancers of the prostate and pancreas [9-11].

Several lines of evidence indicate that Gli1 contributes to breast cancer development and progression. Conditional expression of Gli1 under the regulation of the MMTV promoter induces mammary carcinomas in transgenic mice. These Gli1-induced carcinomas are Estrogen Receptor (ER) $\alpha$ negative and have features reminiscent of the basal subtype of human breast cancers [12]. Overexpression of Gli1 in human breast cancer tissue and cell lines is well-documented [13, 14]. In addition, Gli1 expression has been shown to be an indicator of a poor prognosis in human breast cancers [14-16]. Our prior work found that nuclear localization of Gli1 protein indicates a poor prognosis in women with $\mathrm{ER} \alpha$ negative and triple negative breast cancers (i.e., those breast cancers lacking $\mathrm{ER} \alpha$, Progesterone Receptor (PR) and amplification of Her2/neu [17]), but not in those with ER $\alpha$ positive cancers [16].

Although it has been shown that Gli1 predicts a poor outcome in $\mathrm{ER} \alpha$ negative and triple negative breast cancers, the functions of Gli1 in these cancer types have not been extensively studied. To examine the role of Gli1 in the progression of ER $\alpha$ negative breast cancers, we studied whether modulation of Gli1 expression would influence the migration, invasion and metastasis of cell lines representative of $\mathrm{ER} \alpha$ negative breast cancer. In addition, we found that Gli1 up-regulates the expression of the matrix metalloproteinase (MMP) MMP-11 in these breast cancer cell lines and studied its contribution to Gli1induced migration and invasion. Herein, we provide evidence that Gli1 promotes the migration, invasion, and metastasis of $\mathrm{ER} \alpha$ negative breast cancer.

\section{Materials and methods}

Cell lines and culture conditions

The MDA-MB-231 (231) breast cancer cell line was a gift from Dr. Janet Price, MD Anderson Cancer Center (Houston, TX), and was maintained in Dulbecco's Modification of Eagle's Medium (DMEM) supplemented with $10 \%$ fetal bovine serum (FBS). The SUM1315 cells were a gift of Dr. Stephen Ethier, Karmanos Cancer Institute (Detroit, MI), and maintained in Ham's F-12 media supplemented with 5\% FBS, Insulin $(10 \mu \mathrm{g} / \mathrm{ml})$, and Epidermal Growth Factor (EGF) $(20 \mathrm{ng} / \mathrm{ml})$. MCF10A cells were purchased from the American Type Culture Collection and were maintained as previously described [18].

\section{Production of viral supernatants and transduction}

For expression of Gli1, the pLJD-HA-Gli1 retroviral construct and its corresponding empty vector control were gifts of Dr. Michael Ruppert [19]. Retroviral supernatants were prepared from Bing cells, and 231 and MCF10A cells were transduced as described previously [20]. After transduction, cells were mass selected with $500-700 \mu \mathrm{g} / \mathrm{ml} \mathrm{G} 418$ for at least 2 weeks. For silencing Gli1 expression, lentiviral supernatants were prepared using the pLKO.1-puro constructs containing shRNA targeting human Gli1 (TRCN0000020484, TRCN0000020488; Mission shRNA plasmid DNA, Sigma-Aldrich, Inc.) or a non-targeting control (NT) shRNA (Sigma-Aldrich, Inc.), as per the manufacturer's protocol. Transduction of 231 cells was followed by mass selection in $20 \mu \mathrm{g} / \mathrm{ml}$ puromycin for at least 3 days. For expression of Gli3R, the pLenti6/ U6-Gli3R lentiviral construct and its corresponding vector control (pLenti6/U6- $\beta$-galactosidase) were gifts of Dr. Bradley Yoder, University of Alabama at Birmingham (Birmingham, AL). Lentiviral supernatants were prepared from $293 \mathrm{~T}$ cells, and 231 cells were transduced as described above. 
Quantitative, reverse transcription PCR

RNA was extracted and subjected to DNase pretreatment prior to cDNA synthesis (High-Capacity cDNA Reverse Transcription kit, Applied Biosystems, Inc.). Primer and probe sets for Gli1, MMP-11 and Ribosomal Protein Large 0 (RPLP0) were purchased from Applied Biosystems (TaqMan Gene Expression Assays-on-Demand, Hs00171790_ m1, Hs00968295_m1 and Hs99999902_m1, respectively). Gene assays were performed using TaqMan Universal PCR Master Mix (Applied Biosystems, Inc.). Fluorescent signal data were collected by the Applied Biosystems Prism 7700 Sequence Detection System. RPLP0 was used as the internal reference. Relative expression values were calculated using the $\Delta \Delta \mathrm{CT}$ method.

\section{Western blot analysis}

For detection of Gli1 and cleaved poly (ADP-ribose) polymerase (PARP), cells were lysed in RIPA lysis buffer (50 mM Tris- $\mathrm{HCl}$ at $\mathrm{pH} 7.4,2 \mathrm{mM}$ dithiothreitol, $1 \%$ Triton X-100, 10\% glycerol, $1 \mathrm{mM}$ phenylmethylsulfonyl fluoride, and $7 \times$ protease inhibitor cocktail (Roche Applied Science)). Fifty micrograms of total protein was separated on 4-15\% gradient gels and transferred to nitrocellulose membranes. The membranes were blocked with $5 \%$ dry milk in $0.1 \%$ PBS-T for $1 \mathrm{~h}$ at room temperature, followed by incubation with the following primary antibodies individually at $4{ }^{\circ} \mathrm{C}$ overnight: a mouse monoclonal antibody to HA (1:1,000 dilution, clone 16B12, Covance, Inc.), a rabbit polyclonal antibody to Gli1 (1:2,500 dilution, a gift of Dr. Michael Ruppert), a mouse monoclonal antibody to cleaved PARP (1:1,000 dilution, Asp214, Cell Signaling Technology), or a mouse monoclonal antibody to $\beta$-actin (1:20,000 dilution, Sigma-Aldrich, Inc.). Secondary detection was achieved with horseradish peroxidase (HRP)-conjugated secondary antibodies (Biorad Laboratories) and chemiluminescent HRP substrate.

For detection of secreted MMP-11, $1.5 \times 10^{6}$ cells were plated in a $60-\mathrm{mm}$ dish. After attachment, the cells were washed with cold phosphate buffered saline (PBS) and $2.0 \mathrm{ml}$ of serum-free DMEM was added to each plate. Forty-eight hours later, the medium was collected and centrifuged. The volume of medium loaded for protein separation was normalized to the numbers of cells on each plate at the time of media collection. A lysate of a human cell line containing a high level of MMP-11 protein (ThermoScientific, MS-1035-PCL) was included as a positive control. The remaining procedure was as described above except that the membranes were incubated with mouse monoclonal antibody to MMP-11 (1:500 dilution, clone SL3.05, Neomarkers/ThermoFisher Scientific).
Transwell migration and invasion assays

For transwell migration assays, $1 \times 10^{5}$ cells were plated in 24-well inserts (8- $\mu \mathrm{m}$ pore size, BD Biosciences). For SUM1315 cells, cells were incubated in medium with $2 \%$ FBS on the transwell inserts (i.e., top well), and medium containing 5\% FBS was placed in the bottom well. After $24 \mathrm{~h}$, cells on the upper surface of the transwell filter were removed, the filters were stained with hematoxylin and eosin, and the number of cells that migrated through the filters was counted in 5, random $200 \times$ microscopic fields per filter. For 231 cells, the same procedure was utilized except that the top well contained DMEM medium supplemented with $1 \%$ FBS and the bottom well contained DMEM with $20 \%$ serum. For MCF10A cells, the top well contained maintenance medium with $2 \%$ horse serum and the bottom well contained maintenance medium with $5 \%$ horse serum. For invasion assays, the same experimental procedures as for transwell migration assays were used except that the 24-well inserts were coated with growth factor-reduced Matrigel ( $8-\mu \mathrm{m}$ pore size, BD Biosciences).

\section{Transfection of siRNA}

To silence endogenous Gli1 expression in breast cancer cell lines, $50 \mathrm{nM}$ of 2 different siRNAs (Stealth RNAi siRNA sets, Invitrogen) targeting Gli1 were transfected using Lipofectamine RNAiMAX (Invitrogen) according to the manufacturer's protocols. Experiments were performed 48-72 h after transfection. To silence MMP-11 expression, $50 \mathrm{nM}$ of a mixture of four different siRNAs (Smartpool siRNA, Dharmacon) targeting MMP-11 were transfected using Dharmafect transfection reagent (Dharmacon), as per the manufacturer's instructions. Experiments were performed $72 \mathrm{~h}$ after transfection.

\section{MTT assay}

To measure cell growth, 5,000 cells per well were plated in a 96 well plate, and MTT assay was performed using CellTiter $96^{\circledR}$ Non-Radioactive Cell Proliferation Assay (Promega), according to the manufacturer's protocols.

\section{Immunostaining for $\mathrm{Ki}-67$}

Cells on coverslips were fixed in $70 \%$ ethanol, dehydrated in graded alcohols, permeabilized in acetone, rehydrated, and treated with $3 \%$ hydrogen peroxide followed by incubation with $3 \%$ goat serum. Cells were incubated with a rabbit polyclonal antibody to Ki-67 (dilution 1:50, Zymed/Invitrogen) for $1 \mathrm{~h}$. Secondary detection was accomplished using a streptavidin-biotin system, as previously described [21]. The percentage of Ki-67 labeled 
cells was determined after counting of cells in random, $200 \times$ microscopic fields. A minimum of 500 cells was counted.

\section{Treatment with HPI-1}

HPI-1 (Hedgehog Pathway Inhibitor-1) was purchased from TimTec, Inc. and dissolved in dimethyl sulfoxide (DMSO). Cells were treated with 5 and $10 \mu \mathrm{M}$ HPI-1 in DMEM containing $0.5 \%$ FBS. The medium was changed every other day.

\section{Experimental (tail vein) metastasis assay}

231 cells were transduced to express shRNA targeting Gli1 (shGli1) or the NT control and maintained in selection medium for 10 days. Adherent, viable cells were washed and suspended in sterile Hank's balanced salt solution. $2.5 \times 10^{5}$ cells were injected intravenously into the lateral tail veins of 3 to 4-week-old, female, athymic mice (nu/nuFoxn1, Harlan Labs) to evaluate lung colonization. The five groups of animals consisted of parental, non-transduced cells and cells transduced with shGli1-1, shGli1-2, a combination of shGli1-1/2, and the NT control. After approximately 6 weeks, the mice were euthanized and the lungs were removed and fixed in neutral-buffered formalin. The number of surface metastases to the lungs was determined by examination under a dissecting microscope, and the diameter of each metastasis was estimated with an ocular micrometer. The volume of each metastasis was calculated using the formula $(4 / 3) \pi r^{3}$ [22].

\section{Data analysis}

Comparison of migration, invasion, optical density, absorbance (MTT assay), Ki-67-labeling, and the numbers and volumes of metastases was accomplished using the unpaired $t$ test with Welch's correction or one-way ANOVA with Tukey post-test. Only $P$ values less than 0.05 were regarded as statistically significant.

\section{Results}

Over-expression of Gli1 promotes migration and invasion of MDA-MB-231 breast cancer cells

To investigate the function of Gli1 in migration and invasion of ER $\alpha$ negative breast cancers, Gli1 was overexpressed and silenced in MDA-MB-231 (231) cells and transwell migration and invasion assays were performed. We utilized 231 cells for these experiments because they are negative for $\mathrm{ER} \alpha, \mathrm{PR}$ and amplification of Her2/neu
[23], were derived from metastatic breast cancer [23], are capable of metastasizing in xenograft models [24], and express a high level of Gli1 relative to an epithelial cell line derived from benign breast (i.e., MCF10A cells) (Supplemental Data, Fig. 1). HA-tagged Gli1 was expressed by retroviral transduction followed by mass selection. Gli1 over-expression was confirmed by quantitative RT-PCR (QRT) (Fig. 1a) and immunoblotting with anti-HA and anti-Gli1 antibody (Fig. 1b). For transwell migration assays, the number of Gli1 over-expressing 231 cells (231Gli1) and empty vector control cells (231-Vector) that traversed the filters toward a serum gradient was counted after $24 \mathrm{~h}$. There was a significant enhancement of migration by Gli1 overexpression $(P=0.002, t$ test $)$ (Fig. 1c). For transwell invasion assays, the number of cells invading through basement membrane material toward a serum gradient after $24 \mathrm{~h}$ was counted. Overexpression of Gli1 also caused a significant increase in invasion ( $P=0.027, t$ test) (Fig. 1d). Growth of 231 cells was not influenced by over-expression of Gli1 (Supplemental Data, Fig. 2a). Over-expression of Gli1 in a noncancerous breast cell line with a low level of Gli1 expression (Supplemental Data, Fig. 1), MCF10A, also resulted in an increase in migration and invasion (Supplemental Data, Fig. 3).

Reduction of Gli1 expression and activity decreases migration and invasion of $\mathrm{ER} \alpha$ negative breast cancer cells

To further demonstrate the role of Gli1 in migration and invasion, Gli1 was silenced by siRNAs targeting Gli1 in 231 cells and transwell migration and invasion assays were performed. Each siRNA achieved a 70-80\% reduction in Gli1 mRNA expression relative to a non-targeting siRNA negative control (NT) (Fig. 2a). Silencing Gli1 expression significantly decreased transwell migration $(P<0.001$, ANOVA) and invasion $(P<0.001$, ANOVA) of the 231 cells (Fig. 2b, c). Cell growth was not affected by the short term silencing of Gli1 by siRNA (Supplemental Data, Fig. 2b).

Gli1 is a major activator of Gli-mediated transcription, and it is also a direct target of Gli-mediated transcription in most cell types [2]. Therefore, another approach to reducing Gli1 expression is to inhibit Gli-mediated transcription. The repressor form of Gli3 (Gli3R) is an inhibitor of Glimediated transcription. Gli3R is derived from full-length Gli3 after proteolytic cleavage and lacks amino acids C-terminal to the zinc finger domain [25]. To reduce Glimediated transcription and Gli1 expression, Gli3R was expressed in 231 cells (231-Gli3R) by lentiviral transduction. Overexpression of Gli3 in comparison to the vector control (231-Vector) was confirmed by QRT (Fig. 2d). 

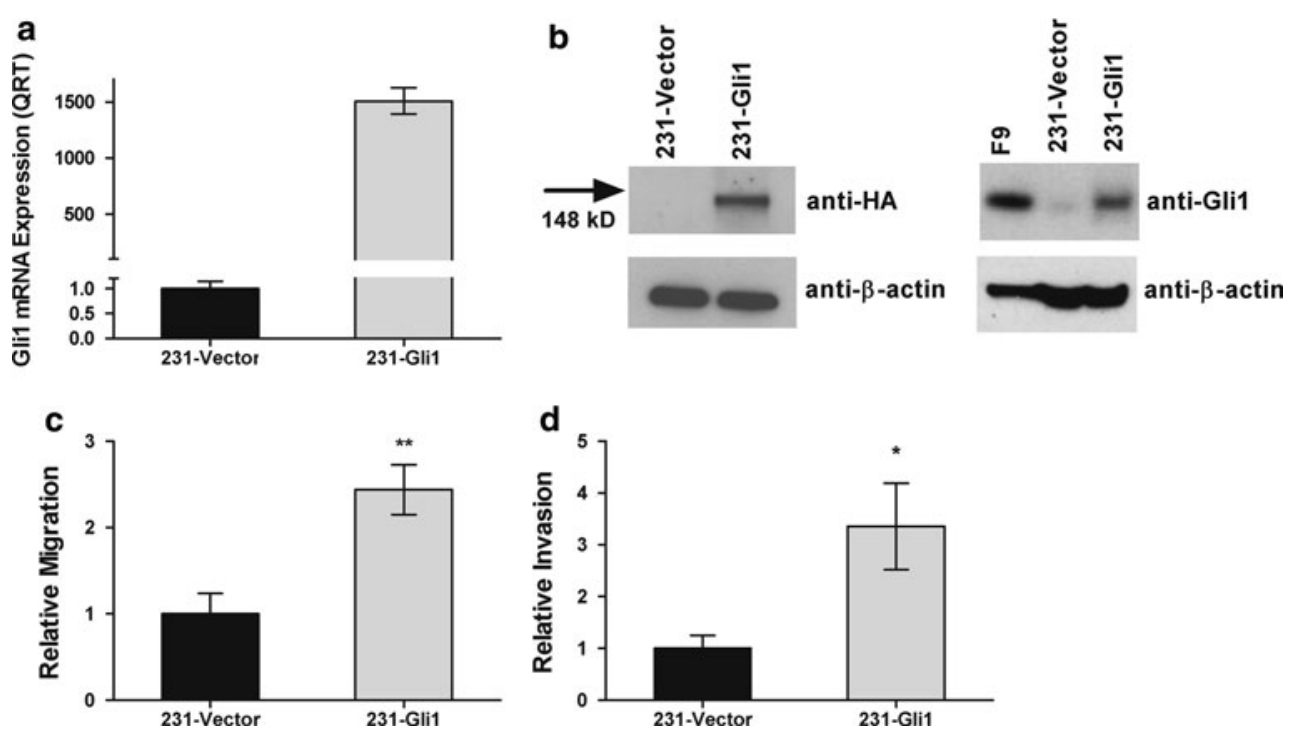

Fig. 1 Over-expression of Gli1 enhanced migration and invasion of MDA-MB-231 breast cancer epithelial cells. a HA-tagged Gli1 was over-expressed by transduction (pLJD-HA-Gli1) of MDA-MB-231 (231-Gli1) cells followed by mass selection. Quantitative RT-PCR (QRT) confirmed an increase in Gli1 mRNA expression in 231-Gli1 in comparison to the empty vector control cells (231-Vector). Overexpression was confirmed prior to each experiment. b Western blot analysis with anti-HA confirmed that HA-tagged Gli1 was overexpressed in 231-Glil cells. Over-expression was also confirmed using a polyclonal antibody that recognizes Gli1 (anti-Gli1). F9 cells are a teratocarcinoma cell line with a high Gli1 expression and are a positive control. $\beta$-actin was also probed for as a loading control. c Transwell migration assays were performed for $24 \mathrm{~h}$. The number of cells that migrated through the transwell filter was increased in 231-Gli1 cells. Data were normalized to the vector control and are the mean and standard error of three independent experiments performed in triplicate $(P=0.002, t$ test). d Transwell invasion assays through basement membrane material were performed for $24 \mathrm{~h}$. The number of cells that traversed the transwell filter was increased in 231-Gli1 cells. Data were normalized to the vector control and are the mean and standard error of three independent experiments performed in triplicate $(P=0.027, t$ test $)$
Correspondingly, expression of Gli1 was inhibited by approximately $50 \%$ in 231-Gli3R cells (Fig. 2e), and transwell migration and invasion of 231 cells was significantly inhibited by expression of Gli3R $(P=0.039$ and $P<0.001, t$ test, respectively) (Fig. 2f, g). Expression of Gli3R for the time period required for the migration and invasion assays had no effect on cell growth (Supplemental Data, Fig. 2c) Therefore, by modulating expression of Gli1 via a variety of approaches, we have demonstrated that Gli1 promotes the migration and invasion of 231 cells.

To extend this finding to another ER $\alpha$ negative breast cancer cell line, Glil expression was also silenced in SUM1315 cells using siRNA [23]. SUM1315 cells, like 231 cells, are ER $\alpha$ and PR negative and lack Her2/neu amplification. They express Gli1 at a relatively high level (Supplemental Data, Fig. 1), were derived from a metastatic breast cancer [23], and are capable of metastasizing in xenograft models [26]. Reduction of Gli1 expression in SUM1315 by siRNA (Fig. 3a) significantly inhibited their migration and invasion over a $24 \mathrm{~h}$ time period $(P<0.001$ for both, ANOVA) (Fig. 3b, c). Also similar to MDAMB-231 cells, short-term reduction in Gli1 expression had no effect on cell growth (Supplemental Data, Fig. 2d). Taken together, our data strongly support that Gli1 promotes the migration and invasion of $\mathrm{ER} \alpha$ negative breast cancer cells.
Gli1 regulates the expression of MMP-11 in ER $\alpha$ negative breast cancer cells

To identify a potential down-stream mediator of Gli1 that is responsible for the increase in migration and invasion induced by Gli1, we quantified expression of MMP-11 mRNA and protein in 231-Gli1 and vector control cells. MMP-11 was of particular interest because its expression in breast cancer, either in cancer stroma or cancer epithelial cells, is predictive of a poor prognosis [27, 28]. Additionally, expression of MMP-11 in hepatocellular carcinoma cell lines has been shown to promote their migration and metastasis [29]; however, such a role for MMP-11 in breast cancer has not been evaluated. MMP-11 mRNA was upregulated by overexpression of Gli1 as assessed by QRT (Fig. 4a). Immunoblotting for MMP-11 protein demonstrated an increase in the secretion of cleaved, active MMP-11 protein in the conditioned medium of 231-Gli1 cells compared to the conditioned medium of the vector control cells (Fig. 4b). MMP-11 is processed intracellularly to its enzymatically active form by a Golgi-associated proteinase Furin, which cleaves the $65 \mathrm{kD}$ MMP-11 zymogen to the $45 \mathrm{kD}$ active form [30]. In some cell types, the $45 \mathrm{kD}$ active enzyme is the predominant secreted form [30]; however, in other cell types, including 231 cells, both 

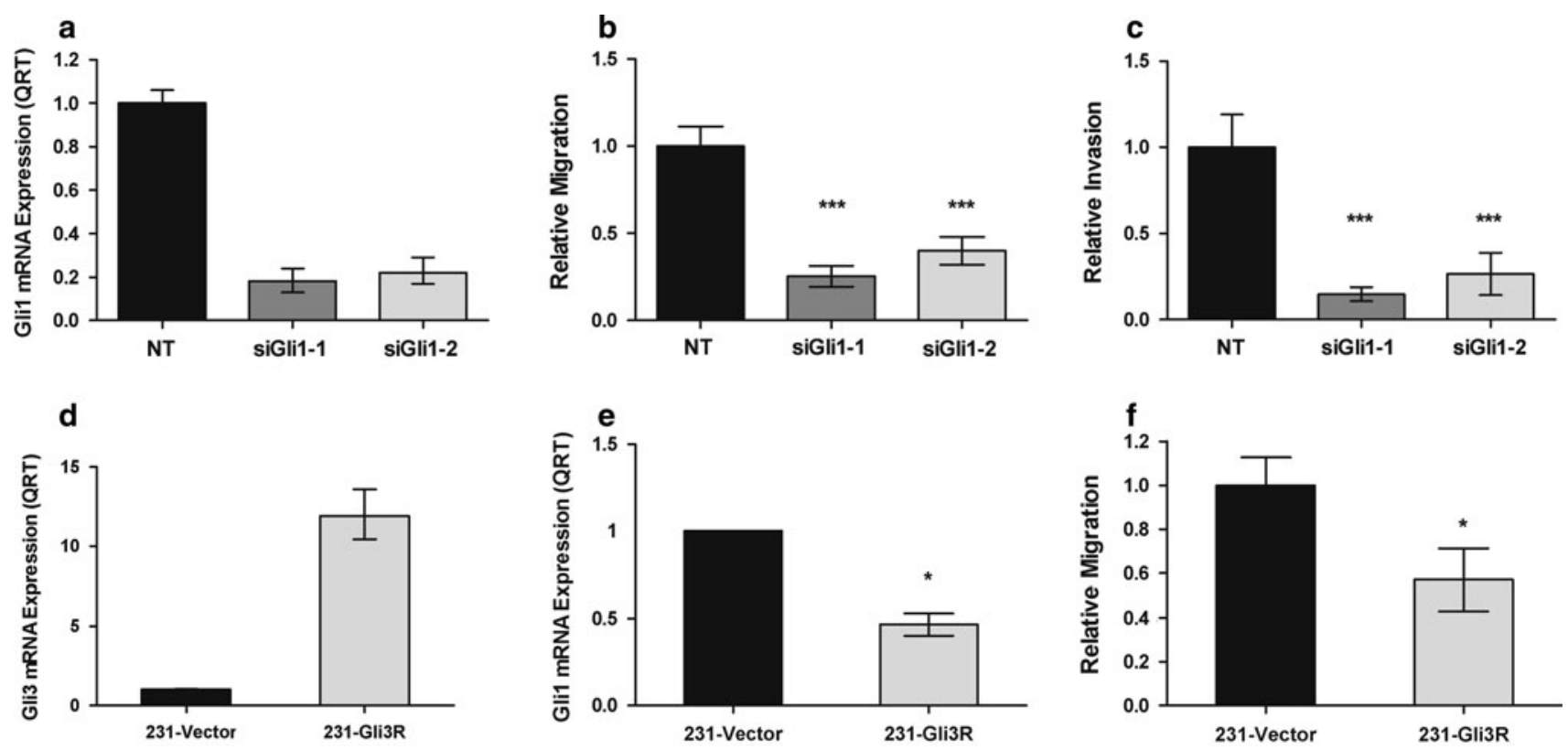

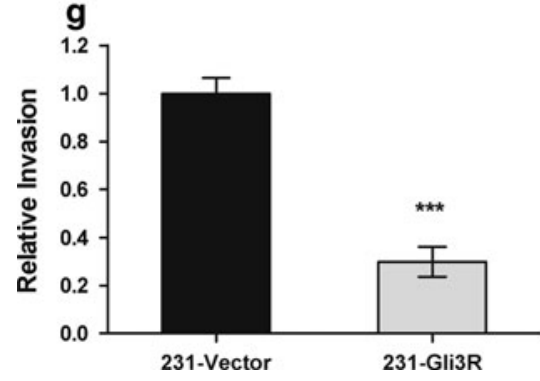

Fig. 2 Reduction of Gli1 expression significantly decreased migration and invasion of 231 cells. a QRT analysis demonstrated decreased Gli1 mRNA expression in 231 cells $48 \mathrm{~h}$ after transfection of 2 different siRNAs targeting Gli1 (siGli1-1, siGli1-2) compared with a non-targeting siRNA control (NT). Decreased expression was confirmed prior to each experiment. b and c Transwell migration (b) and invasion (c) assays were performed for $24 \mathrm{~h}$. Silencing Gli1 significantly decreased migration $(P<0.001$, ANOVA) and invasion $(P<0.001$, ANOVA $)$ of 231 cells in comparison to the NT control cells. Data were normalized to the NT control and are the mean and standard error of three independent experiments performed in triplicate. d The repressor form of Gli3 (Gli3R) was expressed by

the active enzyme and the inactive proenzyme are secreted $[30,31]$. Silencing Gli1 expression by siRNA decreased MMP-11 expression in both 231 and SUM1315 cells as quantified by QRT (Fig. 4c). Taken together, our data indicate that MMP-11 is up-regulated by Gli1 in these ER $\alpha$ negative breast cancer cell lines.

Gli1-induced migration and invasion is mediated by MMP-11

To determine whether Gli1 enhances migration and invasion by upregulating MMP-11 in 231 cells, we silenced MMP-11 expression in 231-Gli1 cells using siRNA lentiviral transduction (pLenti6-Gli3R) of 231 cells (231-Gli3R). Gli3 overexpression in comparison to the vector control (231-Vector) was confirmed by QRT analysis. Increased expression was confirmed prior to each experiment. e Expression of Gli3R down-regulated Gli1 mRNA as measured by QRT in 231 cells. Data are the mean and standard error of three independent experiments $(P=0.022, t$ test $)$. $\mathbf{f}$ and $\mathbf{g}$ Expression of Gli3R decreased migration (f) $(P=0.039$, $t$ test $)$ and invasion $(\mathrm{g})(P<0.001, t$ test $)$ of 231 cells $($ after $24 \mathrm{~h})$ in transwell migration and invasion assays as compared with the vector control. Data are normalized to the vector control and are the mean and standard error of three independent experiments performed in triplicate

(Fig. 4d) resulting in a reduction in secretion of MMP-11 protein in 231-Gli1 cells to a level similar to that in 231 cells without over-expression of Gli1 (Fig. 4e, f). Transwell migration and invasion assays were performed for $24 \mathrm{~h}$. Migration and invasion of 231-Gli1 cells with reduction of MMP-11 expression was decreased to the level exhibited by 231-Vector cells $(P=0.006$ and $P=0.001$, respectively, $t$ test) (Fig. $4 \mathrm{~g}$, h). In addition, silencing MMP-11 in 231 cells which do not over-express Gli1 (231-vector) also resulted in a decrease in migration and invasion $(P<0.001$ for both, $t$ test) (Supplemental Data, Fig. 4). Our data provide evidence that MMP-11 is important for the migration and invasion of 231 cells, and 

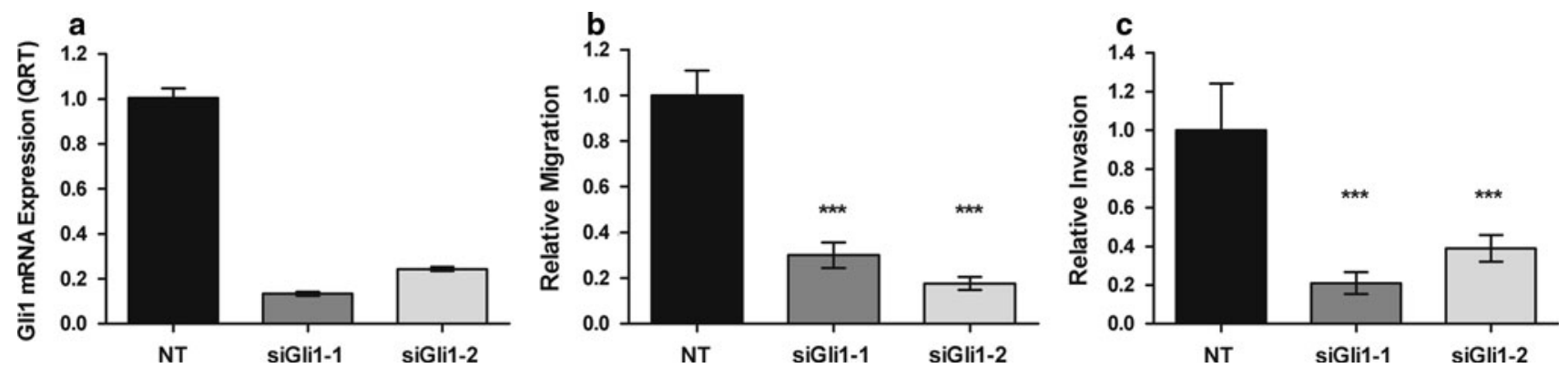

Fig. 3 Reduction of Gli1 expression significantly impaired migration and invasion of ER $\alpha$ negative SUM1315 breast cancer cells. a QRT analysis demonstrated that endogenous Gli1 expression was reduced in SUM1315 by transfection of two different siRNAs targeting Gli1 (siGli1-1, siGli1-2) in comparison to the non-targeting control (NT). Decreased expression was confirmed prior to each experiment. $\mathbf{b}$ and

c Silencing Gli1 expression significantly inhibited migration (b) $(P<0.001$, ANOVA $)$ and invasion $(\mathbf{c})(P<0.001$, ANOVA $)$ of SUM1315 cells (after $24 \mathrm{~h}$ ) in transwell migration and invasion assays. Data are normalized to the NT control and are the mean and standard error of three independent experiments performed in duplicate or triplicate

its increase resulting from over-expression of Gli1 mediates the promotion of migration and invasion induced by Gli1.

Sustained inhibition of Gli1 expression and activity reduces growth of MDA-MB-231 breast cancer cells

Analysis of the role of Gli1 in metastasis assays in vivo requires sustained suppression of Gli1 expression or activity over a 6 week period. We wanted to achieve a sustained reduction in Gli1 expression by at least $70 \%$ to maximize the phenotypic effect of Gli1 suppression. We were unable to achieve this degree of sustained suppression of Gli1 with either the siRNA or expression of Gli3R. Therefore, we utilized shRNA, delivered by lentiviral transduction, to achieve a sustained reduction in Gli1 at 2 weeks (western blot analysis, Fig. 5a) and after 1 month (QRT, Fig. 5b). To compare the effect of Gli1 silencing by shRNA with our prior results using siRNA and Gli3R, we employed the MTT assay to measure cellular metabolic activity as a surrogate for cell viability or growth. Similar to the results with siRNA and Gli3R (Supplemental Data, Fig. $2 b$ and $c)$, there was no significant inhibition of growth 5 days after transduction (Fig. 5c). However, with sustained suppression of Gli1 expression for 10 days, growth was markedly reduced $(P<0.001$, ANOVA) (Fig. 5c). To determine whether this decrease in growth was a result of a decrease in proliferation or increase in apoptosis, proliferation was assessed by immunocytochemistry for Ki-67 and apoptosis was assessed by western blot analysis for cleaved poly (ADP-ribose) polymerase (PARP) after sustained reduction of Gli1. PARP is a nuclear enzyme involved in DNA repair and is a substrate for Caspase 3 cleavage during apoptosis. PARP was increased in 231-shGli1 as compared to the NT control cells $(P<0.001$, ANOVA) (Fig. $5 \mathrm{~d}, \mathrm{e})$. There was also a significant, but modest (12\%), decrease in Ki-67 labeling with
Gli1 reduction ( $P=0.02, t$ test) (Fig. 5f). Therefore, the decrease in growth with sustained Gli1 suppression was a result of increased apoptosis and, to some extent, decreased proliferation.

To achieve long term inhibition of Gli1 by another mechanism, we treated 231 cells continuously for 8 days with the small molecular inhibitor of Gli-mediated transcription, HPI-1. HPI-1 was identified as inhibitor of Glimediated transcription by a high throughput screen in NIH3T3 cells [32]. We confirmed the ability of HPI-1 to inhibit Gli-mediated transcription by demonstrating a dose dependent decrease in Gli1 expression after treatment with HPI-1 for $48 \mathrm{~h}$ (Fig. 5g). Then, we treated 231 cells with HPI- 1 for 3 and 8 days and assessed cell growth by MTT assay. After 3 days of treatment, there was no decrease in cell growth (Fig. 5h), similar to the results seen with suppression of Gli1 expression by shRNA, siRNA and Gli3R. However, on day 8, cell growth was significantly reduced $(P<0.001$, ANOVA) (Fig. 5h), similar to the effect of sustained suppression of Gli1 expression by shRNA (Fig. 5c).

Long-term silencing of Gli1 expression inhibits experimental metastasis of MDA-MB-231 breast cancer cells

To confirm that suppression of Gli1 expression by shRNA also inhibits migration and invasion, similar to silencing by siRNA, we performed migration and invasion assays, as described above, 3 days after transduction with shRNA targeting Gli1 (shGli1-1 and shGli1-2). Similar to the siRNA experiments, there was a significant decrease in migration and invasion of the 231 cells transduced with shGli1 (231-shGli1) after $24 \mathrm{~h}(P<0.001$ for migration and invasion, ANOVA) (Fig. 6a, b). To provide direct evidence that Gli1 is involved in the metastasis of ER $\alpha$ negative breast cancer, experimental, tail-vein metastasis 

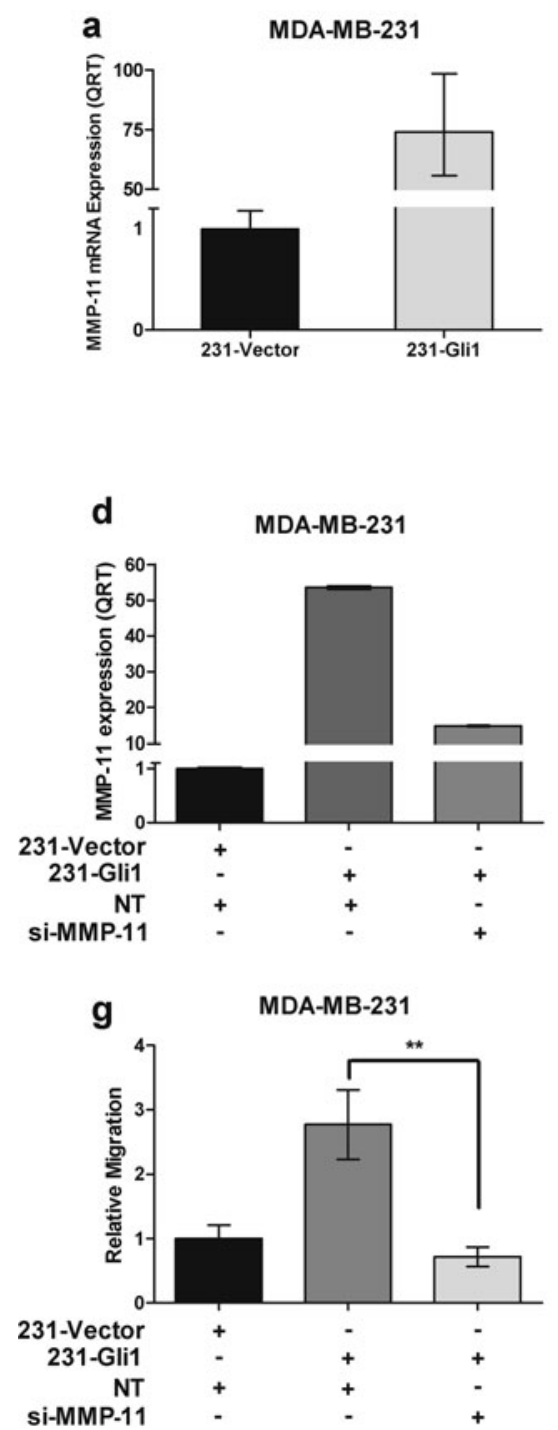

b
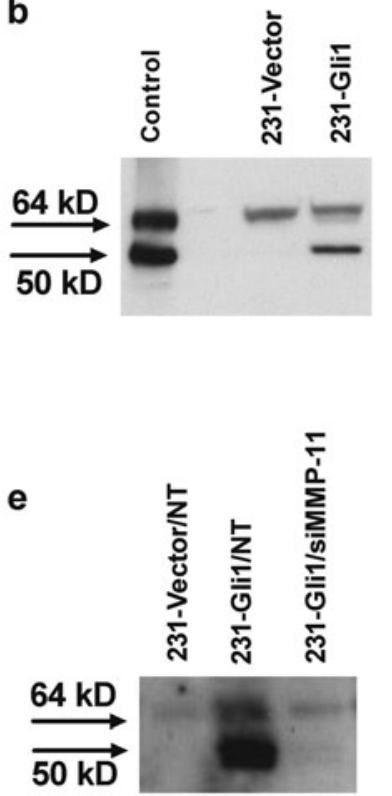

h

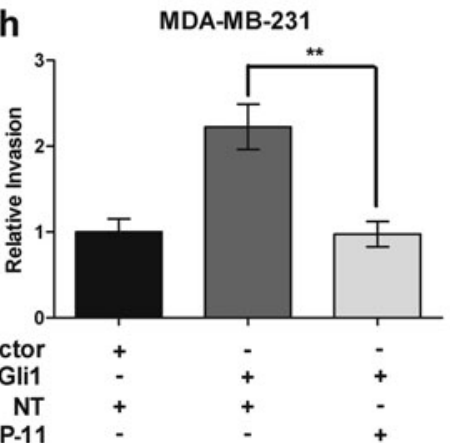

C
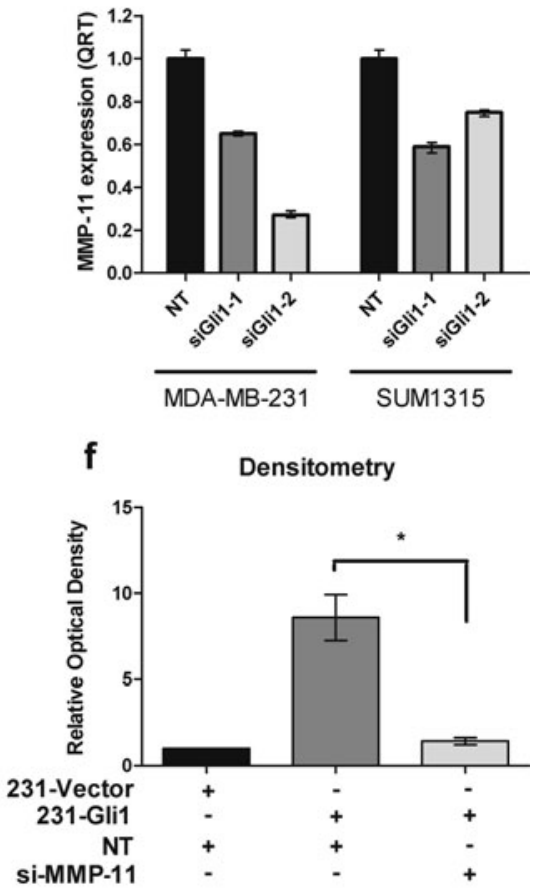

Fig. 4 Expression of MMP11 is up-regulated by Gli1, and MMP11 is important for Gli1-mediated migration and invasion of 231 cells. a Over-expression of Gli1 resulted in an up-regulation of MMP11 mRNA in 231-Gli1 cells as measured by QRT. Data are the mean and standard deviation $(P<0.001, t$ test $)$. b Western blot analysis demonstrated elevated expression of the secreted, active form of MMP-11 protein in conditioned media harvested from 231-Gli1 cells in comparison to the conditioned medium from the same number of vector control cells (231-Vector). The immunoblot demonstrated two separate bands of $\sim 65 \mathrm{kD}$ (latent proenzyme form) and $\sim 45 \mathrm{kD}$ (active form) of secreted MMP-11 protein. A cell lysate with a high level of MMP11 (ThermoScientific) was included as a positive control (Control). This immunoblot is representative of at least four separate experiments. c QRT analysis demonstrated that silencing Gli1 using siRNA reduces expression of MMP-11 mRNA in 231 and SUM1315 cells in comparison to the non-targeting control (NT). The data are the mean and standard error of two (231) or three (SUM1315)

assays were conducted with the 231 cells transduced with shGli1-1, shGli1-2 or a combination of shGli1-1 and shGli1-2 and compared to the parental and non-targeting (NT) controls. After transduction, the cells were grown in experiments performed in triplicate $(P<0.01$ for each, ANOVA). d QRT analysis indicated a reduced expression of MMP-11 after transfection of siRNAs targeting MMP-11 (si-MMP11) in comparison to a non-targeting siRNA control (NT) in 231-Gli1 cells. e and f Western blot analysis of conditioned media from 231-Vector/NT, 231-Gli1/NT and 231-Gli1 with siRNA targeting MMP-11 (231-Gli1/ siMMP-11) demonstrated a reduction in secreted MMP-11 protein in 231-Gli1/siMMP-11 in comparison to 231-Gli1 to level that was similar to 231-Vector/NT. This experiment was repeated three times and densitometric representation of these experiments in $\mathbf{f}$ is normalized to 231-Vector/NT $(P=0.034, t$ test $) . \mathbf{g}$ and $\mathbf{h}$ Transwell migration (g) and invasion (h) assays were performed after silencing MMP-11 in 231-Gli1 cells. Silencing MMP11 significantly decreased transwell migration $(P=0.006, t$ test $)$ and invasion $(P=0.001$, $t$ test) of 231-Gli1 cells (after $24 \mathrm{~h}$ ). Data are normalized to the vector control and are the mean and standard error of three independent experiments performed in triplicate

selection medium for 12 days and subsequently injected via the tail vein. Suppression of Glil expression in the 231-shGli1 cells was confirmed by QRT on the day prior to injection (data not shown). Approximately 6 weeks after 

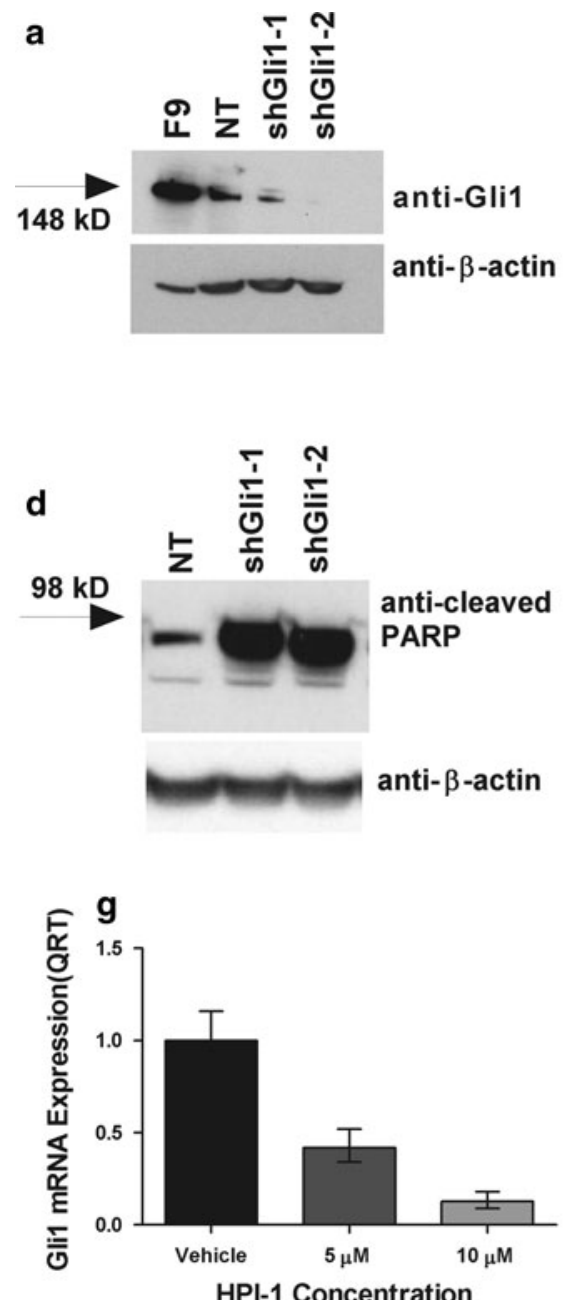

Fig. 5 Sustained inhibition of Gli1 expression by shRNA or HPI-1 impaired growth of 231 cells. a Reduction in Gli1 expression 2 weeks after transduction of shRNA targeting Gli1 (shGli1-1, shGli1-2) in 231 cells was verified by western blot analysis using a rabbit polyclonal antibody (anti-Gli1). $\beta$-actin is a loading control. F9 cells are a teratocarcinoma cell line with a very high expression of Gli1 and are a positive control. b QRT analysis demonstrated that a reduction in Gli1 mRNA was maintained for 1 month after transduction of shGli1-1 and shGli1-2 in 231 cells in comparison to transduction of a non-targeting shRNA control (NT). c Cell growth was measured at 5 and 10 days after transduction of shRNA targeting Gli1 in 231 cells by MTT assay. Reduced expression of Gli1 for 5 days had little impact on cell growth, whereas, after 10 days of inhibition of Gli1 expression there was a significant decrease in cell growth $(P<0.001$, ANOVA). Data are the mean and standard error of three independent experiments performed in triplicate. d To determine whether there was an increase in apoptosis in 231 cells with sustained reduction in Gli1 expression by shRNA (shGli1-1, shGli1-2), western blot analysis for cleaved PARP was performed on day 9 after transduction with shRNA targeting Gli1. The immunoblot was also probed for $\beta$-actin as a loading control. There was an increase in cleaved PARP, as indicated by an increase in the $89 \mathrm{kD}$ cleavage product, in the shGli1-

injection, the numbers and diameters of pulmonary metastases were assessed by visual inspection of the pleural surfaces under a dissecting microscope with the aid
C MTT Assay After Transduction
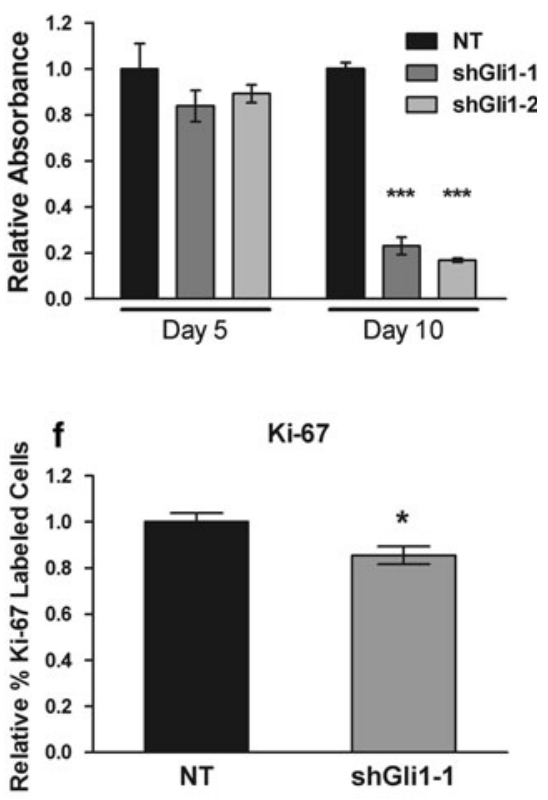
optical density of the bands corresponding to cleaved PARP on immunoblots from three replicate, independent experiments was greater in the shGlil cells in comparison to the NT control cells $(P<0.001$, ANOVA). The optical densities for PARP were normalized to the optical densities of the corresponding bands for $\beta$-actin. f 231 cells with sustained suppression of Gli1 expression (shGli1-1) and the corresponding NT control cells were immunostained for Ki67 on day 9 after transduction. The percentages of Ki-67 labeled cells (a minimum of 500 cells was counted) was significantly lower in the shGli-1 cells in comparison to the NT control $(P=0.02, t$ test $)$. Data are the mean and standard error of three independent experiments. g 231 cells were treated with HPI-1 (5 and $10 \mu \mathrm{M})$, an antagonist of Gli-mediated transcription, for $48 \mathrm{~h}$. Inhibition of Gli-mediated transcription was indicated by a reduction in Gli1 mRNA, as quantified by QRT, in treated cells in comparison to the vehicle control. Data are the mean and standard deviation $(P<0.01$, ANOVA). h MTT assay was performed on 231 cells treated with HPI- 1 for 3 and 8 days. HPI-1 did not decrease growth after 3 days of treatment, but inhibited growth after 8 days of treatment $(P<0.001$, ANOVA). Data are the mean and standard error of three independent experiments performed in triplicate

of an ocular micrometer. The groups of mice injected with shGli1 exhibited a marked reduction in the numbers of metastases in comparison to the mice injected with the NT 

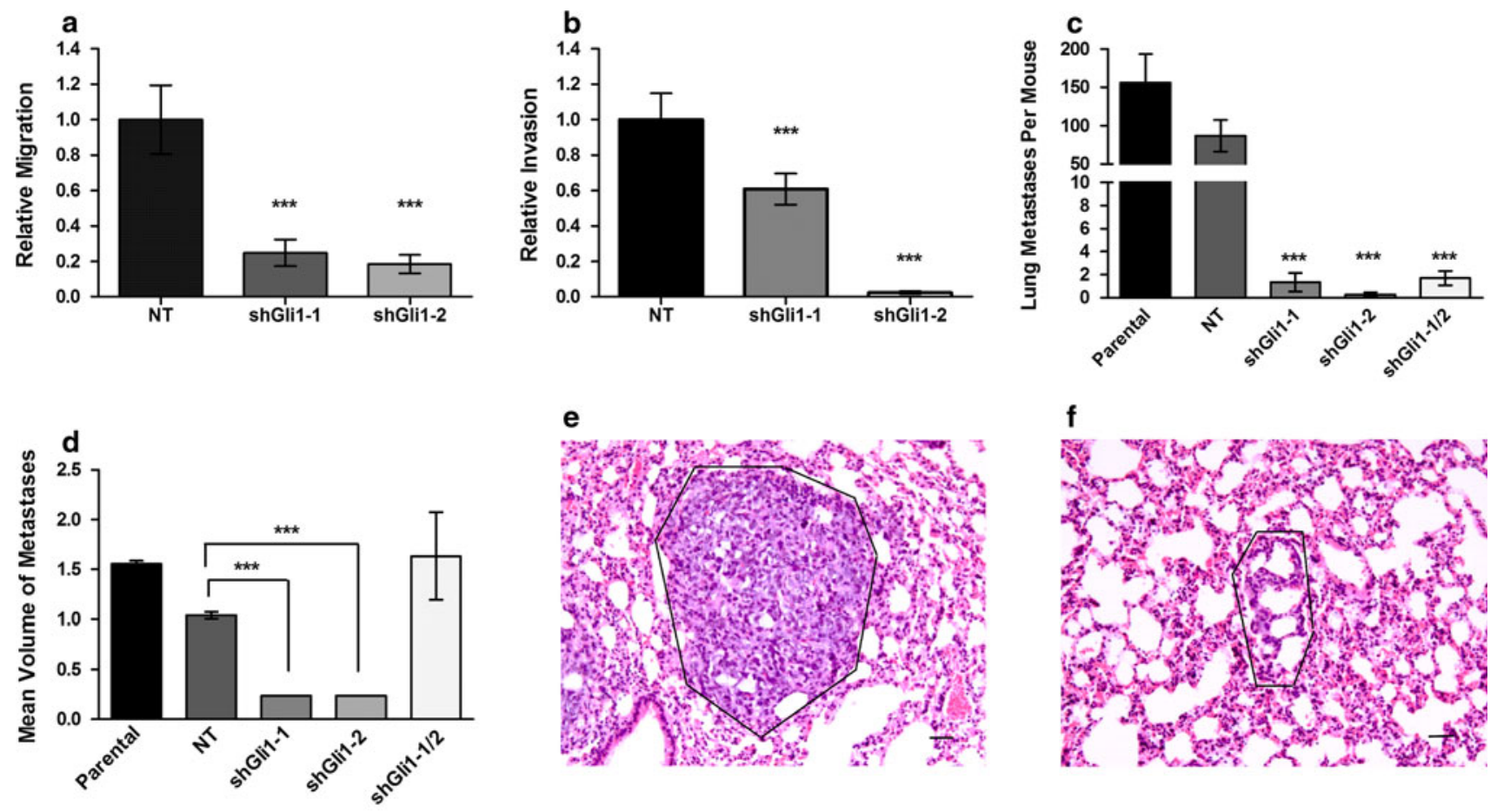

g

h
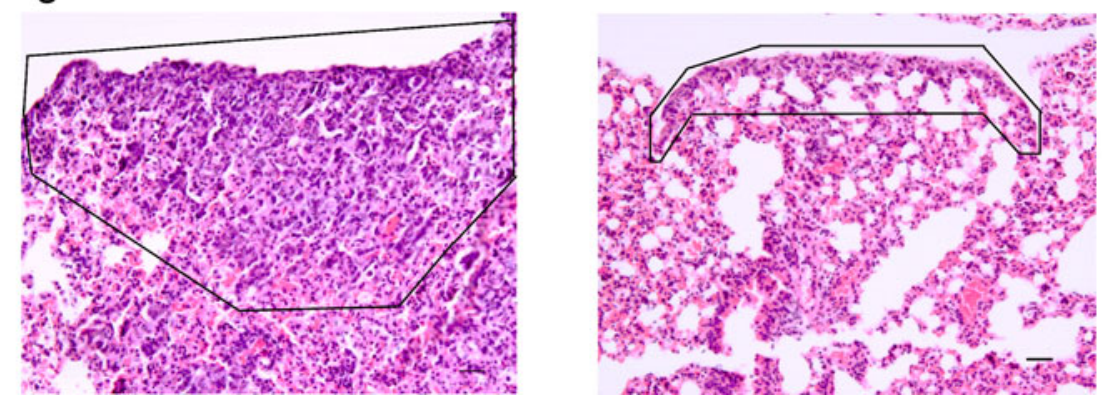

Fig. 6 Reduction of Gli1 expression by shRNA inhibits migration, invasion and metastasis. a and b Reduced expression of Gli1 by different shRNA in 231 cells (shGli1-1, shGli1-2) markedly decreased migration (a) $(P<0.001$, ANOVA) and invasion $(\mathbf{b})(P<0.001$, ANOVA) after $24 \mathrm{~h}$ in comparison to NT control cells. Data are the mean and standard error of three independent experiments performed in triplicate. c Silencing Gli1 significantly inhibited the number of metastasis of 231 cells to the lungs of female, athymic nude mice $(P<0.001$, ANOVA $)$ in an experimental metastasis assay. Parental 231 cells $(\mathrm{n}=10$ animals) or 231 cells transduced with the NT control $(\mathrm{n}=10)$, shGli1-1 $(\mathrm{n}=6)$, shGli1-2 $(\mathrm{n}=7)$ or a combination of the two shGli1 $(\mathrm{n}=10)$ were injected into the tail-veins. The numbers of metastases in the lungs were determined approximately 6 weeks after injection. $\mathbf{d}$ The volumes of each pulmonary metastasis was also estimated and the mean volume of the metastases in the lungs of the mice injected with shGli1-1 and shGli2-1 was smaller

control cells $(P<0.001$, ANOVA) (Fig. 6c). An estimated volume for each metastasis was calculated from the maximum diameter measured at the pleural surface. The mean volumes of the metastases was significantly smaller in two of the 231-shGli1 groups in comparison to the NT control groups $(P<0.001, t$ test) (Fig. 6d). However, in the than the metastases in the NT control group $(P<0.001$ for both comparisons, $t$ test), but this was not the case for the shGli1-1/2 group because of several larger metastases identified at the pulmonary surfaces in this group. e and $\mathbf{f}$ Histologic examination confirmed that the metastases in the shGli1 groups were smaller than those in the NT and parental controls. Representative metastases (outlined in black) from the NT control (e) were larger than those in shGlil groups (shGli1-2 shown here) (f) in hematoxylin \& eosin (H\&E)-stained histologic sections $(\times 200$ original magnification, scale bar $=50 \mu \mathrm{m})$. $\mathbf{g}$ and $\mathbf{h}$ H\&E-stained sections of the metastases (outlined in black) identified at the pulmonary surfaces revealed that the metastatic cells only coated the pleural surface and did not extend deeply into the parenchyma in shGli1-1/2 mice (h), in contrast to those found at the pulmonary surfaces of the NT $(\mathbf{g})$ and parental control mice $(\times 200$ original magnification, scale bar $=50 \mu \mathrm{m}$ )

231-shGli1-1/2 group, there were three larger metastases identified at the pulmonary surfaces that raised the mean volume. Histologic analysis confirmed the decreased numbers of metastases in the 231-shGli1 groups and confirmed that the metastases were indeed smaller in the 231-shGli1 groups compared to the NT and parental 
controls (Fig. 6e, f). Histologic analysis also revealed that the "larger" metastases identified at the surfaces of the lungs in the 231-shGli1-1/2 group only coated the pleural surface and did not invade or extend deeply into the underlying parenchyma, as was the case in the NT and parental control groups (Fig. 6g, h). Therefore, even these "larger" metastases in the 231-shGli1-1/2 group were relatively small in comparison to the controls.

\section{Discussion}

Our data indicate that Gli1 is important for the growth, migration, invasion and metastasis of $\mathrm{ER} \alpha$ negative breast cancer. Our findings are supported by the work of others also demonstrating that knockdown of Gli1 by RNA interference in two $\mathrm{ER} \alpha$ negative breast cancer cell lines, MDA-MB-231 and SKBR3, reduced both cell growth and invasion [33]. Silencing of Gli1 was also shown to inhibit the metastasis of the MDA-MB-435 cancer cell line, but whether this cell line represents ER $\alpha$ negative breast cancer or melanoma is currently debated [34-36]. Therefore, our data provide new evidence that Gli1 is important for the metastasis of $\mathrm{ER} \alpha$ negative breast cancer. In addition, we report that Gli1 expression results in an increase in MMP11 , which mediates the pro-migratory and pro-invasive activities of Gli1 in the ER $\alpha$ negative MDA-MB-231 breast cancer cell line.

Metastasis is a multi-step process that requires cancer cells to detach from the main tumor, to migrate and invade through stroma and intravasate, to survive in the circulatory system and arrive at a secondary site, and to extravasate, invade and grow at the secondary site. In the tail-vein metastasis assay, only the later steps in this process are tested, specifically survival in the circulatory system, and extravasation, invasion and growth at the secondary site. Our in vitro data indicating that Gli1 is important for cell growth and survival, migration and invasion suggest that Gli1 promotes metastasis by advancing several processesby promoting cell survival and growth in the lung and by promoting migration and invasion through the vascular wall and into the surrounding pulmonary parenchyma. The smaller sizes of the metastases with Gli1 silencing indicate the importance of Gli1 in promoting growth, while the smaller number of metastases may result from inhibition of the pro-survival effect of Gli1 or its role in promoting migration and invasion from the vasculature and into the lung parenchyma.

The cell lines included in this study, 231 and SUM1315, are two of the few breast cancer cell lines that are capable of metastasis in animal models. Expression of Gli1 mRNA is higher in these two cancer cells (Supplemental Fig. 1) than in MCF10A cells, which are derived from benign breast and are non-tumorigenic and non-metastatic. While Gli1 is relatively high in these metastatic lines, it is difficult to directly correlate the level of endogenous Gli1 in a cancer cell line and its relative migratory, invasive or metastatic capability because many different genes and complex molecular pathways contribute to their invasive and metastatic phenotypes. Gli1 is one of many molecules that regulate migration, invasion and metastasis. This is underscored by the many different genes that have been identified as being important in breast cancer metastasis, including those that direct metastases to the lung and brain $[37,38]$. Of those 13 genes included in the gene expression signature associated with metastasis to the lung and those 11 genes associated with metastasis to the bone [37, 38], only one, CXCR4, has thus far been identified as a target of Gli1-mediated transcription. However, several of the many other genes that contribute to the metastasis of breast cancer are known to be up-regulated by Gli1. These include Osteopontin, Snail, Platelet-derived Growth Factor, and MMP-9 [9, 19, 39-43].

In this study, we demonstrate that MMP-11 is also up-regulated by Gli1 and that it contributes to the migration and invasion induced by Gli1 in 231 cells. Therefore, a reduction in MMP-11, and possibly other Gli1 targets, inhibits migration and invasion relatively rapidly. Unlike most MMP family members, MMP-11 does not cleave major components of the extracellular matrix [44]. Several potential substrates of MMP-11 have been identified and include Collagen VI, Laminin Receptor, $\alpha 1$-Proteinase Inhibitor, and Insulin Like Growth Factor (IGF) Binding Protein 1 [30, 45-47]. MMP-11 was first identified from a cDNA library of breast carcinoma tissues and its expression is up-regulated in invasive breast cancers compared to ductal carcinoma in situ (DCIS) [48]. MMP-11 is expressed at a high level in the fibroblastic stroma of breast cancers, but is also expressed in the cancer epithelial cells [27, 48-50]. Expression of MMP-11 in either the stromal or epithelial compartment in breast cancer is predictive of a poor disease outcome [27].

MMP-11 has been previously shown to contribute to the migration and adhesion of a hepatocellular carcinoma cell line, but the underlying molecular mechanism was not elucidated [29]. A possible mechanism arises from the observation that over-expression of MMP-11 in MCF7 cells resulted in activation of Erk1/2 and Akt [51]. Activated Akt regulates several proteins that are involved in cell migration and invasion, either by direct phosphorylation of these proteins or by modulation of their upstream regulators [52]. The Erk/MAPK pathway regulates different processes involved in cell motility, including focal adhesion disassembly and the activity of the Rho family of small GTPases, which participate in cell migration and invasion [53]. The mechanism through which MMP-11 
activates Erk1/2 and Akt has not been specifically elucidated; however, it has been demonstrated that MMP-11 can release extracellular IGF-1 bound to IGF Binding Protein 1 , which is a substrate of MMP-11 [45]. IGF-1, by signaling through the IGF-1 receptor can activate both Erk1/2 and Akt $[54,55]$. Stimulation of IGF-1 signaling by MMP11 in MDA-MB-231 cells was shown to account for, at least in part, an increased tumor take and growth of xenografts of 231 cells overexpressing MMP-11 and to enhance the expression of molecules involved in cell migration and invasion [56].

Our present study also demonstrates that sustained inhibition of Gli1 for 8-10 days, rather than a short-term inhibition, is required to decrease the growth of 231 cells. This finding suggests that Gli1 regulates the production of one or more pro-survival signals, possibly secreted proteins, which require several days after down-regulation of Gli1 to become sufficiently diminished in quantity or activity that cell viability can no longer be maintained. Alternatively, prolonged culture may alter cellular function/homeostasis such that the cells become more susceptible to the effects of decreased Gli1 expression and activity.

Our data in the ER $\alpha$ negative and triple negative 231 and SUM1315 cell lines also demonstrate the potential for targeting Gli1 and the use of inhibitors of Gli-mediated transcription in the treatment of $\mathrm{ER} \alpha$ negative and triple negative breast cancers. Triple negative breast cancers are particularly aggressive and currently lack effective targeted therapies [17]. Therefore, there is a critical need for the development of new therapeutic strategies, such as targeting Gli1 via antagonists of Gli-mediated transcription, for the treatment of breast cancer. Further work in both in vitro and in vivo models of ER $\alpha$ negative and triple negative breast cancer will be required to establish the efficacy of targeting Gli1 using small molecule Gli1 antagonists.

Acknowledgments We thank Drs. Janet Price, Stephen Ethier, Michael Ruppert and Bradley Yoder for their contributions of reagents for use in this work. This work was funded by the American Cancer Society (RSG-05-207-01-TBE), the Susan G. Komen Foundation (BCTR0707453), the National Institutes of Health (1R03CA130057), the Department of Defense (BC083907), and the National Foundation for Cancer Research.

Open Access This article is distributed under the terms of the Creative Commons Attribution Noncommercial License which permits any noncommercial use, distribution, and reproduction in any medium, provided the original author(s) and source are credited.

\section{References}

1. Fernandez-Zapico ME (2008) Primers on molecular pathways GLI: more than just Hedgehog? Pancreatology 8(3):227-229
2. Stecca B, Ruiz IAA (2010) Context-dependent regulation of the GLI code in cancer by HEDGEHOG and non-HEDGEHOG signals. J Mol Cell Biol 2(2):84-95

3. Dennler S, Andre J, Alexaki I et al (2007) Induction of sonic hedgehog mediators by transforming growth factor-beta: Smad3dependent activation of Gli2 and Gli1 expression in vitro and in vivo. Cancer Res 67(14):6981-6986

4. Ji Z, Mei FC, Xie J et al (2007) Oncogenic KRAS activates hedgehog signaling pathway in pancreatic cancer cells. J Biol Chem 282(19):14048-14055

5. Stecca B, Mas C, Clement V et al (2007) Melanomas require HEDGEHOG-GLI signaling regulated by interactions between GLI1 and the RAS-MEK/AKT pathways. Proc Natl Acad Sci USA 104(14):5895-5900

6. Noubissi FK, Goswami S, Sanek NA et al (2009) Wnt signaling stimulates transcriptional outcome of the Hedgehog pathway by stabilizing GLI1 mRNA. Cancer Res 69(22):8572-8578

7. Kinzler KW, Ruppert JM, Bigner SH et al (1988) The GLI gene is a member of the Kruppel family of zinc finger proteins. Nature 332(6162):371-374

8. Hahn H, Wojnowski L, Zimmer AM et al (1998) Rhabdomyosarcomas and radiation hypersensitivity in a mouse model of Gorlin syndrome. Nat Med 4(5):619-622

9. Nagai S, Nakamura M, Yanai K et al (2008) Gli1 contributes to the invasiveness of pancreatic cancer through matrix metalloproteinase-9 activation. Cancer Sci 99(7):1377-1384

10. Karhadkar SS, Steven Bova G, Abdallah N et al (2004) Hedgehog signalling in prostate regeneration, neoplasia and metastasis. Nature 431(7009):707-712

11. Nolan-Stevaux O, Lau J, Truitt ML et al (2009) GLI1 is regulated through Smoothened-independent mechanisms in neoplastic pancreatic ducts and mediates PDAC cell survival and transformation. Genes Dev 23(1):24-36

12. Fiaschi M, Rozell B, Bergstrom A et al (2009) Development of mammary tumors by conditional expression of GLI1. Cancer Res 69(11):4810-4817

13. Mukherjee S, Frolova N, Sadlonova A et al (2006) Hedgehog signaling and response to cyclopamine differ in epithelial and stromal cells in benign breast and breast cancer. Cancer Biol Ther 5(6):674-683

14. Kubo M, Nakamura M, Tasaki A et al (2004) Hedgehog signaling pathway is a new therapeutic target for patients with breast cancer. Cancer Res 64(17):6071-6074

15. ten Haaf A, Bektas N, von Serenyi S et al (2009) Expression of the glioma-associated oncogene homolog (GLI) 1 in human breast cancer is associated with unfavourable overall survival. BMC Cancer 9:298

16. Xu L, Kwon YJ, Frolova N et al (2010) Gli1 promotes cell survival and is predictive of a poor outcome in ERalpha-negative breast cancer. Breast Cancer Res Treat 123(1):59-71

17. Rakha EA, Ellis IO (2009) Triple-negative/basal-like breast cancer: review. Pathology 41(1):40-47

18. Sadlonova A, Novak Z, Johnson MR et al (2005) Breast fibroblasts modulate epithelial cell proliferation in three-dimensional in vitro co-culture. Breast Cancer Res 7(1):R46-R59

19. Louro ID, Bailey EC, Li X et al (2002) Comparative gene expression profile analysis of GLI and c-MYC in an epithelial model of malignant transformation. Cancer Res 62(20):5867-5873

20. Foster KW, Ren S, Louro ID et al (1999) Oncogene expression cloning by retroviral transduction of adenovirus E1A-immortalized rat kidney RK3E cells: transformation of a host with epithelial features by c-MYC and the zinc finger protein GKLF. Cell Growth Differ 10(6):423-434

21. Sadlonova A, Mukherjee S, Bowe DB et al (2007) Human breast fibroblasts inhibit growth of the MCF10AT xenograft model of proliferative breast disease. Am J Pathol 170(3):1064-1076 
22. Welch DR, Neri A, Nicolson GL (1983) Comparison of 'spontaneous' and 'experimental' metastasis using rat 13762 mammary adenocarcinoma metastatic cell clones. Invasion Metastasis 3(2): $65-80$

23. Neve RM, Chin K, Fridlyand J et al (2006) A collection of breast cancer cell lines for the study of functionally distinct cancer subtypes. Cancer Cell 10(6):515-527

24. Kim IS, Baek SH (2010) Mouse models for breast cancer metastasis. Biochem Biophys Res Commun 394(3):443-447

25. Li Y, Zhang H, Choi SC et al (2004) Sonic hedgehog signaling regulates Gli3 processing, mesenchymal proliferation, and differentiation during mouse lung organogenesis. Dev Biol 270(1): 214-231

26. Kuperwasser C, Dessain S, Bierbaum BE et al (2005) A mouse model of human breast cancer metastasis to human bone. Cancer Res 65(14):6130-6138

27. Nakopoulou L, Panayotopoulou EG, Giannopoulou I et al (2002) Stromelysin-3 protein expression in invasive breast cancer: relation to proliferation, cell survival and patients' outcome. Mod Pathol 15(11):1154-1161

28. Engel G, Heselmeyer K, Auer G et al (1994) Correlation between stromelysin-3 mRNA level and outcome of human breast cancer. Int J Cancer 58(6):830-835

29. Jia L, Wang S, Cao J et al (2007) siRNA targeted against matrix metalloproteinase 11 inhibits the metastatic capability of murine hepatocarcinoma cell Hca-F to lymph nodes. Int J Biochem Cell Biol 39(11):2049-2062

30. Pei D, Weiss SJ (1995) Furin-dependent intracellular activation of the human stromelysin-3 zymogen. Nature 375(6528):244-247

31. Delany AM, Canalis E (2001) The metastasis-associated metalloproteinase stromelysin-3 is induced by transforming growth factor-beta in osteoblasts and fibroblasts. Endocrinology 142(4):1561-1566

32. Hyman JM, Firestone AJ, Heine VM et al (2009) Small-molecule inhibitors reveal multiple strategies for Hedgehog pathway blockade. Proc Natl Acad Sci USA 106(33):14132-14137

33. Kameda C, Tanaka H, Yamasaki A et al (2009) The Hedgehog pathway is a possible therapeutic target for patients with estrogen receptor-negative breast cancer. Anticancer Res 29(3):871-879

34. Das S, Harris LG, Metge BJ et al (2009) The hedgehog pathway transcription factor GLI1 promotes malignant behavior of cancer cells by up-regulating osteopontin. J Biol Chem 284(34):22888-22897

35. Rae JM, Creighton CJ, Meck JM et al (2007) MDA-MB-435 cells are derived from M14 melanoma cells-a loss for breast cancer, but a boon for melanoma research. Breast Cancer Res Treat 104(1):13-19

36. Chambers AF (2009) MDA-MB-435 and M14 cell lines: identical but not M14 melanoma? Cancer Res 69(13):5292-5293

37. Kang Y, Siegel PM, Shu W et al (2003) A multigenic program mediating breast cancer metastasis to bone. Cancer Cell 3(6): 537-549

38. Minn AJ, Gupta GP, Siegel PM et al (2005) Genes that mediate breast cancer metastasis to lung. Nature 436(7050):518-524

39. Yoon JW, Kita Y, Frank DJ et al (2002) Gene expression profiling leads to identification of GLI1-binding elements in target genes and a role for multiple downstream pathways in GLI1induced cell transformation. J Biol Chem 277(7):5548-5555

40. Shevde LA, Samant RS, Paik JC et al (2006) Osteopontin knockdown suppresses tumorigenicity of human metastatic breast carcinoma, MDA-MB-435. Clin Exp Metastasis 23(2):123-133
41. Martin MD, Carter KJ, Jean-Philippe SR et al (2008) Effect of ablation or inhibition of stromal matrix metalloproteinase-9 on lung metastasis in a breast cancer model is dependent on genetic background. Cancer Res 68(15):6251-6259

42. Olmeda D, Moreno-Bueno G, Flores JM et al (2007) SNAI1 is required for tumor growth and lymph node metastasis of human breast carcinoma MDA-MB-231 cells. Cancer Res 67(24):11721-11731

43. Jechlinger M, Sommer A, Moriggl R et al (2006) Autocrine PDGFR signaling promotes mammary cancer metastasis. J Clin Investig 116(6):1561-1570

44. Motrescu ER, Rio MC (2008) Cancer cells, adipocytes and matrix metalloproteinase 11: a vicious tumor progression cycle. Biol Chem 389(8):1037-1041

45. Manes S, Mira E, Barbacid MM et al (1997) Identification of insulin-like growth factor-binding protein-1 as a potential physiological substrate for human stromelysin-3. J Biol Chem 272(41): 25706-25712

46. Motrescu ER, Blaise S, Etique N et al (2008) Matrix metalloproteinase-11/stromelysin-3 exhibits collagenolytic function against collagen VI under normal and malignant conditions. Oncogene 27(49):6347-6355

47. Fiorentino M, Fu L, Shi YB (2009) Mutational analysis of the cleavage of the cancer-associated laminin receptor by stromelysin3 reveals the contribution of flanking sequences to site recognition and cleavage efficiency. Int J Mol Med 23(3):389-397

48. Basset P, Bellocq JP, Wolf C et al (1990) A novel metalloproteinase gene specifically expressed in stromal cells of breast carcinomas. Nature 348(6303):699-704

49. Wolf C, Rouyer N, Lutz Y et al (1993) Stromelysin 3 belongs to a subgroup of proteinases expressed in breast carcinoma fibroblastic cells and possibly implicated in tumor progression. Proc Natl Acad Sci USA 90(5):1843-1847

50. Ahmad A, Hanby A, Dublin E et al (1998) Stromelysin 3: an independent prognostic factor for relapse-free survival in nodepositive breast cancer and demonstration of novel breast carcinoma cell expression. Am J Pathol 152(3):721-728

51. Fromigue O, Louis K, Wu E et al (2003) Active stromelysin-3 (MMP-11) increases MCF-7 survival in three-dimensional Matrigel culture via activation of p42/p44 MAP-kinase. Int J Cancer 106(3):355-363

52. Dillon RL, Muller WJ (2010) Distinct biological roles for the akt family in mammary tumor progression. Cancer Res 70(11): 4260-4264

53. Viala E, Pouyssegur J (2004) Regulation of tumor cell motility by ERK mitogen-activated protein kinases. Ann N Y Acad Sci 1030: 208-218

54. Clemmons DR (2007) Modifying IGF1 activity: an approach to treat endocrine disorders, atherosclerosis and cancer. Nat Rev Drug Discov 6(10):821-833

55. Furstenberger G, Senn HJ (2002) Insulin-like growth factors and cancer. Lancet Oncol 3(5):298-302

56. Kasper G, Reule M, Tschirschmann M et al (2007) Stromelysin-3 over-expression enhances tumourigenesis in MCF-7 and MDAMB-231 breast cancer cell lines: involvement of the IGF-1 signalling pathway. BMC Cancer 7:12 